\title{
$\mathrm{M} / \mathrm{W}$ 중계용 주파수 개발 및 재배치 방안 연구
}

\section{Spectrum Deployment and Reallocation for M/W Relay Service}

\author{
강 영 흥
}

Young-Houng Kang

요 약

국내에서는 도서지역의 정보격차 해소를 위해 광대역 인터넷 서비스의 $\mathrm{M} / \mathrm{W}$ 중계 통신망을 구축해 나가고 있다. 도서 통신용으로 장거리 $(13 \mathrm{~km}$ 이상) 전송에 적합하고, $\mathrm{UHD}$ 급 중계 서비스 제공을 위해 강우 및 지형적 특성 감쇠에 강한 $10 \mathrm{GHz}$ 이하 스펙트럼에 대한 요구가 지속적으로 증가하고 있다. 특히 향후 $5 \mathrm{G}$ 이동통신 도입 및 상용화에 따른 트래픽 이 급증할 것으로 예상됨에 따라 프론트홀(fronthaul) 및 백홀(backhaul) 용도의 기존 $\mathrm{M} / \mathrm{W}$ 주파수 이용확대 및 새로운 $\mathrm{M} / \mathrm{W}$ 중계용 주파수 재개발이 필요한 실정이다. 이에 본 연구에서는 $\mathrm{M} / \mathrm{W}$ 중계용 주파수 이용현황 및 문제점 분석을 통해 국내 주파수 정책 환경에 적합한 $\mathrm{M} / \mathrm{W}$ 중계용 주파수 재개발 및 이의 실행방안 등을 제시한다.

\section{Abstract}

In Korea, $\mathrm{M} / \mathrm{W}$ relay networks for broadband Internet service are being built to bridge the information gap in remote island areas. The demand for spectrum below the $10 \mathrm{GHz}$ band is continuously increasing to provide long-haul $(>13 \mathrm{~km})$ transmission for remote islands and reliable ultra-high-definition class relay service in environments with strong rain and where topographical attenuation is a problem. Especially, because the introduction and commercialization of $5 \mathrm{G}$ mobile communication will rapidly increase traffic in the future, expanding the existing $\mathrm{M} / \mathrm{W}$ frequency usage and redeploying the new $\mathrm{M} / \mathrm{W}$ frequency for the fronthaul and backhaul networks will be needed. Therefore, in this study, M/W spectrum deployment and implementation methods suitable to the Korean spectrum policy environment are proposed by analyzing the use trend and problem of $\mathrm{M} / \mathrm{W}$ relay frequencies.

Key words: M/W, Spectrum, Deployment, Fronthaul, Backhaul

\section{I. 서 론}

전파자원은 국가의 소중한 무형자산으로서 무선통신 의 발전과 함께 전파자원의 가치가 더욱 커지고 있다. 과 거에는 석유, 철강, 가스 및 석탄 등이 국가의 중요한 자 원이었으나, 21 세기의 정보화 사회에서는 전파자원도 그
에 못지않게 소중한 자산으로 인식되고 있다. 특히 전파 자원은 국가의 경제발전은 물론 안보나 공공 안전, 재난 구조, 그리고 새로운 과학기술의 탐구 등 그 응용분야가 매우 다양하다. 미국, 영국 등 선진국에서는 이를 체계적 이고, 효율적으로 이용하기 위하여 자국의 전파정책방향 을 설정하고, 이를 기반으로 관련 정책 및 기술개발을 적

\footnotetext{
「본 연구는 2017년도 한국방송통신전파진흥원 위탁연구과제(과제번호: $\mathrm{KCA}$ 연구 2017-01)의 일환으로 수행하였음.」 군산대학교 컴퓨터정보통신공학부(School of Computer, Information \& Communication Engineering, Kunsan National University) · Manuscript received January 11, 2019 ; Revised March 28, 2019 ; Accepted July 4, 2019. (ID No. 20190111-005)

· Corresponding Author: Young-Houng Kang (e-mail: yhkang@kunsan.ac.kr)
} 
극적으로 추진하고 있다 ${ }^{[1],[2]}$.

국내 $\mathrm{M} / \mathrm{W}$ 중계용 주파수는 16 개 대역 $(1.7 \mathrm{GHz} \sim 86$ $\mathrm{GHz}$, 총 7,028 MHz 대역폭)에서 통신중계 및 방송중계용 으로 사용 중이다. 그 무선국수는 5,831 국으로 조사되고 있다. 또한, $10 \mathrm{GHz}$ 이하 $\mathrm{M} / \mathrm{W}$ 대역은 총 8 개 대역으로 $3,020 \mathrm{MHz}$ 폭이며, 현재 $6 \mathrm{GHz}$ 이하 광대역 이동통신 등 신규주파수 분배에 따라 상향 재배치 추세이다 ${ }^{[2]}$.

최근 $\mathrm{M} / \mathrm{W}$ 주파수 이용 효율화 추진 기본계획 수립 (2015년 5월)에 의해 $6 \mathrm{GHz}$ 이하 이동방송 중계용을 6 7 $\mathrm{GHz}$ 대역으로 단계적 상향 - 재배치되고 있다. 또한, 국 내 통신사업자들의 농어촌 광대역 인터넷 사업, 도서무선 시설 공급, 노후 무선설비 대체에 필요한 중계용 주파수 수요 제기가 증가하고 있다. 이에 따라 장거리 전송 수요 에 대해 7 8 GHz 대역에 대한 채널 재배치, 주파수 이용 효율화 및 주파수 공동사용을 추진하여 $10 \mathrm{GHz}$ 이하의 $\mathrm{M} / \mathrm{W}$ 주파수 확보가 매우 시급한 실정이다.

이에 저자는 한국방송통신전파진흥원과 공동으로 장 거리 전송에 적합한 $8 \mathrm{GHz}$ 대역의 중계 채널 재배치, 공 공용 주파수와의 공동사용 방안, $5 \mathrm{G}$ 전송망(백홀, 프런트 홀)용 주파수 확보방안 연구를 수행해 왔다. 우선 도서지 역의 장거리 구간의 중계 주파수 수요에 대응할 수 있도 록 $8 \mathrm{GHz}$ 대역 채널배치 방식 효율화(채널변경, 편파조 정 등)를 수행하였다. 수요가 집중되고 있는 $8 \mathrm{GHz}$ 대역 주파수 추가 확보를 위해 공공용으로 사용 중인 인접 7 $\mathrm{GHz}$ 대역에서 공공-상용 간 주파수 공동 사용하는 방안 을 검토하였다. 또한, 향후 $5 \mathrm{G}$ 이동통신 트래픽 증가로 인해 무선 백홀(backhaul) 전송망 활용 증대가 예상됨에 따라 이를 위한 밀리미터파 이상의 신규 주파수 확보방 안 연구를 진행하였다 ${ }^{[3]}$.

본 연구에서는 국내 $\mathrm{M} / \mathrm{W}$ 국간 중계 주파수 이용효율 의 극대화를 추구하기 위한 주파수 재개발 분석 및 실행 방안 연구를 제시하고자 한다. 이를 위해 II 장에서는 기 존의 $\mathrm{M} / \mathrm{W}$ 링크의 용량 증대방안, II장에서는 국내 $\mathrm{M} / \mathrm{W}$ 주파수 유효이용을 위한 주파수 재배치 방안을 제시한다. IV 장에서는 통신사업자의 수요제기에 따른 중계 채널 재 배치 추진 현황, $\mathrm{V}$ 장에서는 공공-M/W 중계 주파수 공동 사용을 위한 간섭분석 결과를 요약한다. VI장에서는 향후 $5 \mathrm{G}$ 이동통신 백홀 서비스 제공을 위한 $\mathrm{M} / \mathrm{W}$ 주파수 확보
방안을 제시한 후 VII장에서 결론을 내린다.

\section{M/W 용량 증대}

기존의 $\mathrm{M} / \mathrm{W}$ 링크의 용량 증대방안으로 (1) 링크설계에 영향이 없는 패킷 압축 적용, (2) 고차 변조기법을 갖는 적 응형 변조(AM; adaptive modulation) 기법 적용, (3) 2배 전 송용량을 위한 수평/수직편파를 사용하는 XPIC(cross-polarization interference cancelation) 기술과 2개의 XPIC 채널 상에 최적의 밸런스 로드(balance load)를 위한 멀티채널 $2+0$ 구성을 사용할 수 있다. 특정 무선전송에 이러한 기 술들을 이용하면 전체의 전송용량을 증대시킬 수 있다. 예를 들어, $128 \mathrm{QAM}$ 고정변조의 $28 \mathrm{MHz}$ 채널 운영, IP 트 래픽의 $50 \%$ 가 작은 사이즈 패킷으로 구성하면 약 150 $170 \mathrm{Mb} / \mathrm{s}$ 의 기본적인 전송용량을 얻는다. 여기에 그림 1 과 같이 패킷 압축 기술에 의해 $40 \%$ 이득과 $1024 \mathrm{QAM}$ 적응형 변조에 의해 추가적으로 $20 \sim 25 \%$ 의 용량 증대를 가져온다. 또한, $2+0 \mathrm{XPIC}$ 기법을 사용하면 2배의 전송률 을 얻게 되어 최초 $150 \mathrm{Mb} / \mathrm{s}$ (그림 1의 제일 왼쪽 막대)에 서 약 $650 \mathrm{Mb} / \mathrm{s}$ (그림 1 의 제일 오른쪽 막대)로 전송용량 을 증대시킬 수가 있다 ${ }^{[4]}$.

\section{MN 주파수 재배치 방안}

국내 무선국 이용현황을 살펴보면 내륙에는 광케이블 구축 등으로 $\mathrm{M} / \mathrm{W}$ 주파수 수급에 문제가 없어 보이나, 서

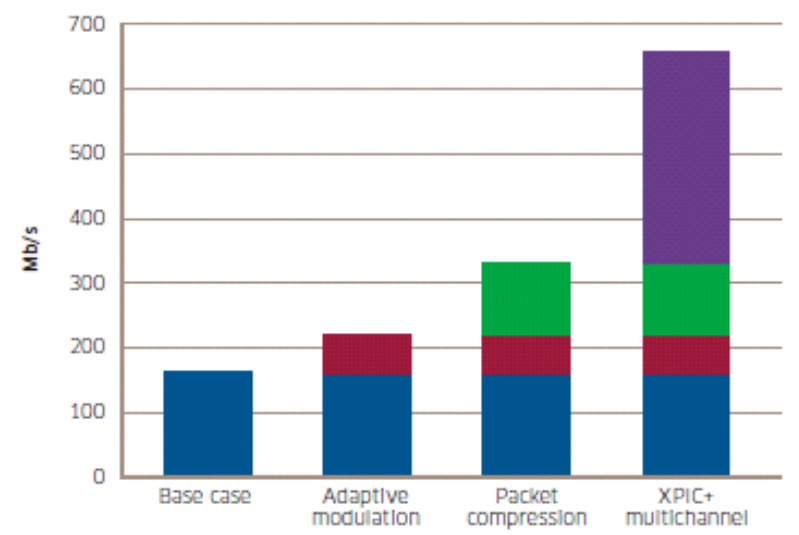

그림 1. 전송용량 증대 ${ }^{[4]}$

Fig. 1. Promotion in transmission capacity ${ }^{[4]}$. 
해안 및 남해안의 주요 도서지역에 $6,8,11 \mathrm{GHz}$ 주파수 대역의 $\mathrm{M} / \mathrm{W}$ 시설이 밀집되어 집중 배치되어 있다.

특히 서해안 도서지역은 거리가 멀어 $\mathrm{M} / \mathrm{W}$ 시설을 구 축하기 위해서는 장거리 홉(hop) 길이를 갖는 낮은 주파 수 대역의 $6 \mathrm{GHz}$ 및 $8 \mathrm{GHz}$ 에 대한 수요가 집중되고 있 다. 그러나 $6 \mathrm{GHz}$ 는 신규 $\mathrm{M} / \mathrm{W}$ 서비스 지정이 불가능하 여 통신사업자들은 $8 \mathrm{GHz}$ 대역을 계속 요구하는 실정이 다. 그림 2에 보이는 바와 같이 $6 \mathrm{GHz}$ 이하 대역의 IMT, C-ITS 신규분배로 방송이동중계는 $6 \mathrm{GHz}$ 대역으로 이전 되었다. 중·장거리 도서지역의 전송수요 증가를 위한 주 파수 이용효율의 고도화 및 향후 $5 \mathrm{G}$ 이동통신 전송망 수 요에 따른 후보대역 발굴이 필요하므로 다음의 4 가지 $\mathrm{M} / \mathrm{W}$ 중계용 주파수 개발 및 재배치 방안을 고려하였다.

(1) 장거리 전송에 적합한 $8 \mathrm{GHz}$ 대역의 통신 중계채널 효율화

- 장거리 전송에 적합한 $10 \mathrm{GHz}$ 이하 중계용 대역인 $6 / 8 \mathrm{GHz}$ 대역 중 $6 \mathrm{GHz}$ 대역은 신규지정이 불가 함에 따라 $8 \mathrm{GHz}$ 대역으로 수요가 집중되고 있음 $-5 \mathrm{G}$ 도입 등 도서지역의 장거리 구간의 중계 주파 수 수요에 대응할 수 있도록 $8 \mathrm{GHz}$ 대역 채널배치 방식 효율화(채널변경, 편파조정 등) 필요

(2) $\mathrm{UHD}$ 방송중계용 무선국 $8 \mathrm{GHz}$ 대역으로 이전

- 최근 국지성 호우 증가로 강우감쇄에 의한 전송장 애 발생우려가 높아짐에 따라 기존 $10 \mathrm{GHz}$ 대역 에서 이용되고 있는 무선국의 $8 \mathrm{GHz}$ 대역으로 이 전 검토 필요
(3) $8 \mathrm{GHz}$ 대역 주파수 추가 확보를 위한 공동사용

- 수요가 집중되고 있는 $8 \mathrm{GHz}$ 대역 주파수 추가 확 보를 위해 공공용으로 사용 중인 인접 $7 \mathrm{GHz}$ 대역 에서 공공-상용 간 주파수 공동 사용하는 방안 검토

(4) $5 \mathrm{G}$ 전송망 주파수 확보 필요

- $5 \mathrm{G}$ 등 이동통신 트래픽 증가로 인해 무선 전송망 (백홀, 프론트홀) 증대가 예상됨에 따라 이를 위한 신규 주파수 확보 필요

\section{M/W 채널 재배치 추진현황}

$\mathrm{M} / \mathrm{W}$ 중계용으로 가능한 16 개 대역 중 주파수 이용계 획, 수요구간의 전송거리 $(5 \sim 40 \mathrm{~km})$, 채널 폭 $(2 \times 40 \mathrm{MHz}$ 대역폭) 등을 고려하여 표 1 과 같이 $8 / 11 \mathrm{GHz}$ 대역을 발 굴하였다.

총 81 개 채널(75개 구간, 채널당 $80 \mathrm{MHz}$ 대역폭) 주파 수 수요제기에 대해 전송기준(전파지정기준은 국간중계 주파수 지정 시 전송거리를 기준으로 $13 \mathrm{~km}$ 이상은 7 8 $\mathrm{GHz}, 13 \mathrm{~km}$ 이하는 $10 \mathrm{GHz}$ 이상을 지정하도록 규정)에 따라 채널 재배치를 진행하였다.

우선 검토대상 45 개 채널(39개 구간) 중 혼간섭 가능성 이 있는 표 2의 총 6 개 채널(6개 구간)에 대해 4 개 채널(4 개 구간)은 채널변경 및 편파조정을 행하였지만, 나머지 2 개 채널은 채널변경 및 편파조정이 불가능하여 지정할 수 없었다. 표 1 의 주요 $\mathrm{M} / \mathrm{W}$ 대역특성과 표 2의 혼간섭 가능성 분석을 통해 신규로 $\mathrm{M} / \mathrm{W}$ 중계용 주파수 수요 중 표 3 과 같이 $8 \mathrm{GHz}$ 대역 14 개 채널(12개 구간)과 $11 \mathrm{GHz}$ 대역 29개 채널(27개 구간) 지정이 완료되었다다.

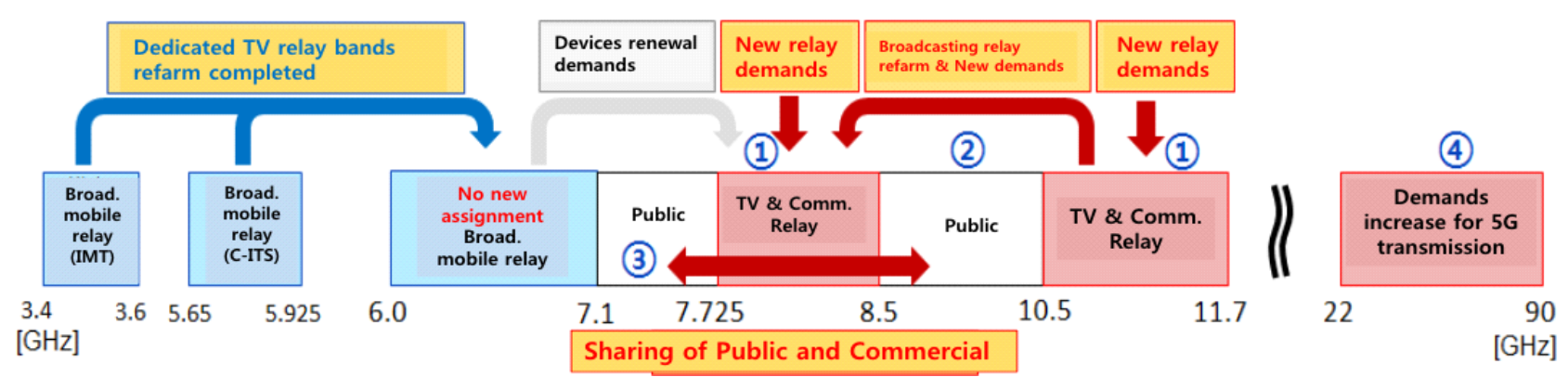

그림 2. $\mathrm{M} / \mathrm{W}$ 주파수 재배치 방안

Fig. 2. A plan for $M / W$ frequency reallocation. 
표 1. 주요 $\mathrm{M} / \mathrm{W}$ 대역 특성

Table 1. Typical characteristics of M/W bands.

\begin{tabular}{|c|l|c|}
\hline Bands & \multicolumn{1}{|c|}{ Comments } & Sharing \\
\hline$<6 \mathrm{GHz}$ & $\begin{array}{l}\cdot<4 \mathrm{GHz} \text { for long distance } \\
\cdot 6 \mathrm{GHz} \text { for mobile broadcast relay }\end{array}$ & No \\
\hline $\begin{array}{c}8 \mathrm{GHz} \text { band } \\
(7,725 \sim 8,350 \mathrm{MHz})\end{array}$ & $\cdot 13 \mathrm{~km}$ or more available & Yes \\
\hline $\begin{array}{c}8 \mathrm{GHz} \text { band } \\
(8,430 \sim 8,500 \mathrm{MHz})\end{array}$ & $\begin{array}{l}\cdot \text { Maximum } 2 \times 20 \mathrm{MHz} \text { available } \\
\text { (Demands: } 2 \times 40 \mathrm{MHz})\end{array}$ & No \\
\hline $11 \mathrm{GHz}$ band & $\cdot 13 \mathrm{~km}$ or less available & Yes \\
\hline $12 \mathrm{GHz}>$ & $\begin{array}{l}\cdot \text { Sharing issues for other use } \\
\text { Unavailable due to rain } \\
\text { attenuation }\end{array}$ & No \\
\hline
\end{tabular}

표 2. 혼간섭 가능성 구간 분석

Table 2. Analysis of the interference potential routes.

\begin{tabular}{|c|c|c|}
\hline Interference P-P & $\begin{array}{c}\text { Assigned } \\
\text { frequency }\end{array}$ & Proposed \\
\hline $\begin{array}{c}\text { Okmasan } \leftrightarrow \\
\text { Hodo }\end{array}$ & $7,745 / 8,055 \mathrm{MHz}$ & $\begin{array}{c}\text { CH change } \\
\text { (ch4 } \rightarrow \text { ch1) }\end{array}$ \\
\hline $\begin{array}{c}\text { Eocheongdo } \leftrightarrow \\
\text { Gusanyeondo }\end{array}$ & $7,905 / 8,215 \mathrm{MHz}$ & $\begin{array}{c}\text { PO arrange } \\
\text { (H } \rightarrow \mathrm{V})\end{array}$ \\
\hline $\begin{array}{c}\text { Nagwoldo } \leftrightarrow \\
\text { Anmado }\end{array}$ & $7,865 / 8,175 \mathrm{MHz}$ & $\begin{array}{c}\mathrm{CH} \text { change } \\
\text { (ch2 } \rightarrow \text { ch4) }\end{array}$ \\
\hline $\begin{array}{c}\text { Nagworldo } \leftrightarrow \\
\text { Yeomsan }\end{array}$ & $7,905 / 8,215 \mathrm{MHz}$ & $\begin{array}{c}\mathrm{CH} \text { change } \\
\text { (ch3 } \rightarrow \text { ch5) }\end{array}$ \\
\hline $\begin{array}{c}\text { Ilsan } \leftrightarrow \\
\text { Manggyeongdae }\end{array}$ & $7,905 / 8,215 \mathrm{MHz}$ & $\begin{array}{c}\text { Unable assigned } \\
\text { for the difficulty } \\
\text { of CH change. or } \\
\text { PO arrange }\end{array}$ \\
\cline { 2 - 3 }
\end{tabular}

\section{$\mathrm{V}$. 공공용 $\mathrm{M} / \mathrm{W}$ 공동사용}

\section{5-1 후보대역}

그림 3과 같이 $\mathrm{M} / \mathrm{W}$ 중계대역 $(8 \mathrm{GHz})$ 과 인접해 장비교 체없이 활용 가능한 7,110 7,725 MHz, 8,350 8,430 MHz, $8,500 \sim 10,200 \mathrm{MHz}$ 대역을 공동사용 후보대역으로 검토 하였다. 후보대역 중 무선국 이용현황, 운용지역, 기술(대 역폭, 출력 등) 및 운용특성(고정, 이동) 등을 고려하여 표 4의 근거에 의해 우선적으로 7,110 7,725 MHz 대역을 검토하게 되었다.
표 3. 신규 $\mathrm{M} / \mathrm{W}$ 채널 지정

Table 3. New M/W channel assignments.

\begin{tabular}{|c|c|c|c|c|}
\hline \multicolumn{2}{|c|}{ Company } & Review CH & Result & Comments \\
\hline \multirow{2}{*}{ A } & $\begin{array}{c}8 \\
\mathrm{GHz}\end{array}$ & $\begin{array}{c}8 \mathrm{CH} \\
(8 \mathrm{P}-\mathrm{P})\end{array}$ & $\begin{array}{c}8 \mathrm{CH} \\
(8 \mathrm{P}-\mathrm{P})\end{array}$ & $\begin{array}{c}\text { Potential Interference } \\
\mathrm{CH} \cdot \mathrm{PO} \text { change }\end{array}$ \\
\hline & $\begin{array}{c}11 \\
\mathrm{GHz}\end{array}$ & $\begin{array}{c}27 \mathrm{CH} \\
(25 \mathrm{P}-\mathrm{P})\end{array}$ & $\begin{array}{c}27 \mathrm{CH} \\
(25 \mathrm{P}-\mathrm{P})\end{array}$ & - \\
\hline \multirow{2}{*}{ B } & $\begin{array}{c}8 \\
\mathrm{GHz}\end{array}$ & $\begin{array}{l}8 \mathrm{CH} \\
(4 \mathrm{P}-\mathrm{P})\end{array}$ & $\begin{array}{c}6 \mathrm{CH} \\
(4 \mathrm{P}-\mathrm{P})\end{array}$ & $\begin{array}{l}2 \mathrm{CH} \text { non-assignment } \\
\text { in interference P-P }\end{array}$ \\
\hline & $\begin{array}{c}11 \\
\mathrm{GHz}\end{array}$ & $\begin{array}{ll}2 & \mathrm{CH} \\
(2 & \mathrm{P}-\mathrm{P})\end{array}$ & $\begin{array}{c}2 \mathrm{CH} \\
(2 \mathrm{P}-\mathrm{P})\end{array}$ & \\
\hline \multirow{2}{*}{ Total } & $\begin{array}{c}8 \\
\mathrm{GHz} \\
\end{array}$ & $\begin{array}{c}16 \mathrm{CH} \\
(12 \mathrm{P}-\mathrm{P})\end{array}$ & $\begin{array}{c}14 \mathrm{CH} \\
(12 \mathrm{P}-\mathrm{P})\end{array}$ & \multirow{2}{*}{$\begin{array}{l}\text { P-P; Point-to-Point, } \\
\text { CH; Channel, } \\
\text { PO; Polarization }\end{array}$} \\
\hline & $\begin{array}{c}11 \\
\mathrm{GHz}\end{array}$ & $\begin{array}{c}29 \mathrm{CH} \\
(27 \mathrm{P}-\mathrm{P})\end{array}$ & $\begin{array}{c}29 \mathrm{CH} \\
(27 \mathrm{P}-\mathrm{P})\end{array}$ & \\
\hline
\end{tabular}

7110

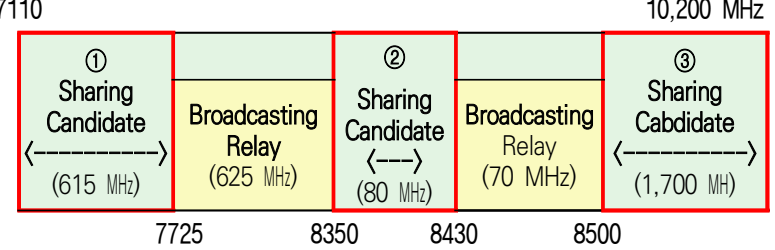

그림 3. 공동사용 후보대역

Fig. 3. Candidate bands for sharing.

표 4. 공동사용 적합성 분석

Table 4. Compatibility analysis for sharing.

\begin{tabular}{|c|c|c|c|c|}
\hline $\begin{array}{c}\text { Candidate } \\
\text { bands(MHz) }\end{array}$ & $\begin{array}{c}\mathrm{BW} \\
(\mathrm{MHz})\end{array}$ & $\begin{array}{l}\text { Use } \\
\text { case }\end{array}$ & Estimations & Sharing \\
\hline $\begin{array}{c}\text { (1) } 7,110 \sim \\
7,725\end{array}$ & 615 & $\begin{array}{l}\mathrm{M} / \mathrm{W}, \\
\text { satellite }\end{array}$ & $\begin{array}{l}\cdot \mathrm{M} / \mathrm{W} \text { relay } \\
\text { (FS) assign- } \\
\text { able }\end{array}$ & Yes \\
\hline $\begin{array}{l}\text { (2) } 8,350 \sim \\
8,430\end{array}$ & 80 & $\begin{array}{c}\text { Traffic } \\
\text { monitoring }\end{array}$ & $\begin{array}{l}\text { - Insufficient } \\
\text { band-width } \\
\text { - Need of pair } \\
\text { frequency } \\
\text { (8 GHz band) }\end{array}$ & No \\
\hline 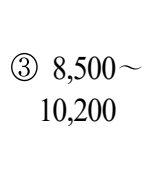 & 1,700 & Radar & $\begin{array}{l}\text { Potential in- } \\
\text { terference in } \\
\text { use of } \mathrm{M} / \mathrm{W} \\
\text { relay }\end{array}$ & No \\
\hline
\end{tabular}




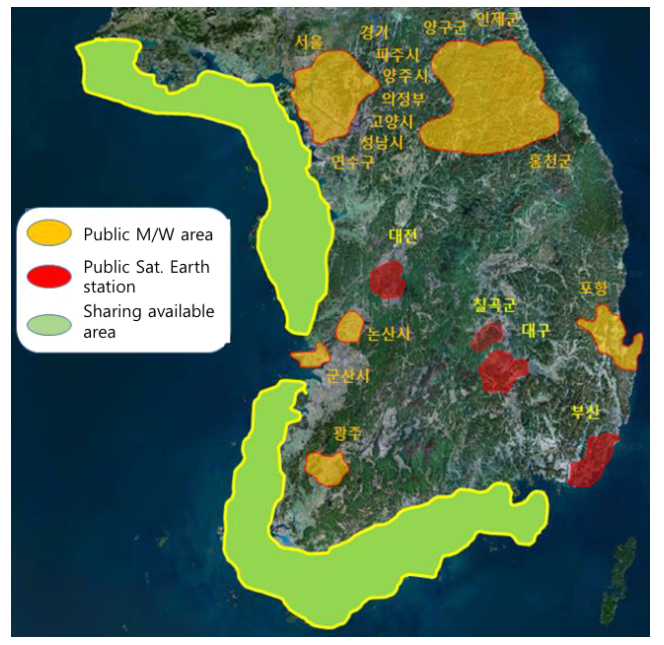

그림 4. 공동사용 가능지역

Fig. 4. Potential sharing area.

$7,110 \sim 7,725 \mathrm{MHz}$ 대역은 지역적으로 공공용 $\mathrm{M} / \mathrm{W}$ 중 계, 위성통신용으로 사용 중이지만 이용지역을 면밀히 검 토한바 지역적으로 공동사용이 가능할 것으로 판단되었 다. M/W 중계는 서울, 부산 등 내륙에서 지역적으로 사용 하고 있어 평상시에 그림 4와 같이 서해 및 남해 도서지 역에서 고정 $\mathrm{M} / \mathrm{W}$ 중계용으로 공동사용이 가능하다. 또 한, WGS(wideband global SATCOM) 및 무궁화 5호 위성 이 하향링크(downlink)로 운용 중이나 출력이 낮고, 운용 채널수가 적어 주파수 공동사용이 가능하다.

\section{5-2 간섭 평가}

공공용의 운용형태 중 고정운용에 대해서는 기 시설자 와의 협의를 통해 채널배치, 기술특성 등을 검토하고, 일 부 간섭 우려 지역에 대해서는 편파변경 등 운용계획 조 정을 통해 간섭문제 해결이 가능하다.

그러나 선박, 기차, 육상 이동체에 장착된 소형 터미널 들은 안테나 포인팅 에러를 가지고 있어 이로 인한 잠재 적 간섭을 발생하는 문제점을 갖고 있다. 이에 적절한 간 섭평가방법을 사용하여 $\mathrm{M} / \mathrm{W}$ 중계망과의 주파수 공동사 용을 검토해야 한다. 여기서는 하향으로 운용되는 고정형 의 위성지구국과 이동형의 선박국과 주파수 공동사용을 위해서는 이들에 간섭을 주는 $\mathrm{M} / \mathrm{W}$ 무선국으로부터의 간 섭평가가 우선되어야 한다.

\section{5-2-1 고정형 위성지구국에 미치는 간섭}

여기서는 7,110 7,725 MHz 대역의 FSS(fixed satellite service) 시스템의 하향링크 주파수 대역을 고려한다. 그 림 5 에 보이는 간섭 시나리오는 위성에서 지구국으로의 하향 FSS 서비스와 주파수 공동사용을 위한 $\mathrm{M} / \mathrm{W}$ 서비스 와의 간섭을 나타내고 있다. FS 송신국으로부터 위성지 구국에 미치는 간섭전력 $\left(I_{F E}\right)$ 은 식 (1)과 같이 표현된다.

$$
\begin{aligned}
& I_{F E}= \\
& \quad P_{F}+G_{F}\left(\theta_{F}\right)-P L(r)+G_{E}\left(\theta_{E}\right) \quad[\mathrm{dBW}]
\end{aligned}
$$

여기서, $P_{F}$ 는 $\mathrm{FS}$ 의 송신전력, $G_{F}\left(\theta_{F}\right)$ 는 $\mathrm{FS}$ 송신국이 수신 위성지국을 향하는 송신안테나 이득, $G_{E}\left(\theta_{E}\right)$ 는 위 성지구국이 $\mathrm{FS}$ 를 바라보는 수신안테나 이득, $P L(r)$ 은 $\mathrm{FS}$ 와 위성지구국간의 거리 $r$ 에 따른 경로손실이다.

또한, $\theta_{F}$ 는 $\mathrm{FS}$ 송신국이 위성지구국을 바라보는 offboresight 각이며, $\theta_{E}$ 는 위성지구국이 FS를 바라보는 offboresight 각이다.

그림 6 은 지구국의 앙각이 $20^{\circ}$ 로 극히 낮은 경우에 거 리에 따른 간섭전력 분포에 대한 3 차원 특성의 예를 나타 내었다. 앙각이 낮은 경우 FS 송신 안테나와 지구국 안테 나간의 방위각에 따른 간섭전력은 FS 송신 메인빔(main beam) 방향에서 백로브(back lobe) 방향보다 강하게 지구 국 수신에 영향을 준다.

간섭평가에 의하면 FS 송신 안테나와 위성지구국간의

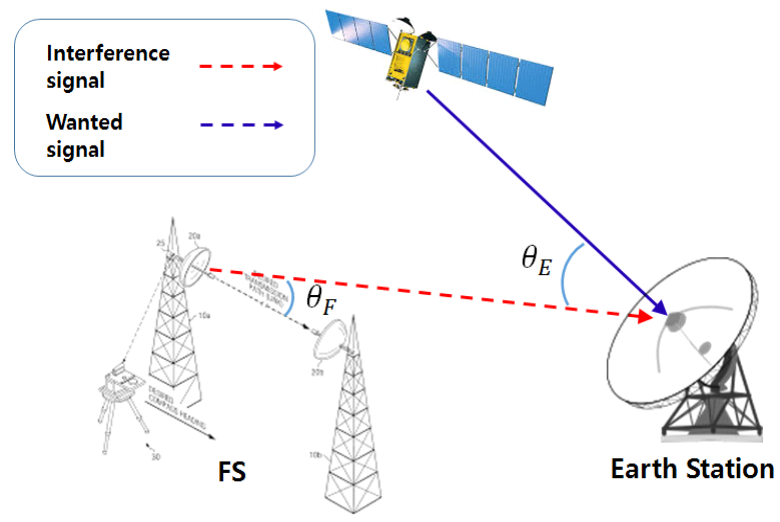

그림 5. 위성지구국에 미치는 $\mathrm{M} / \mathrm{W}$ 간섭

Fig. 5. M/W interference into a satellite earth station. 


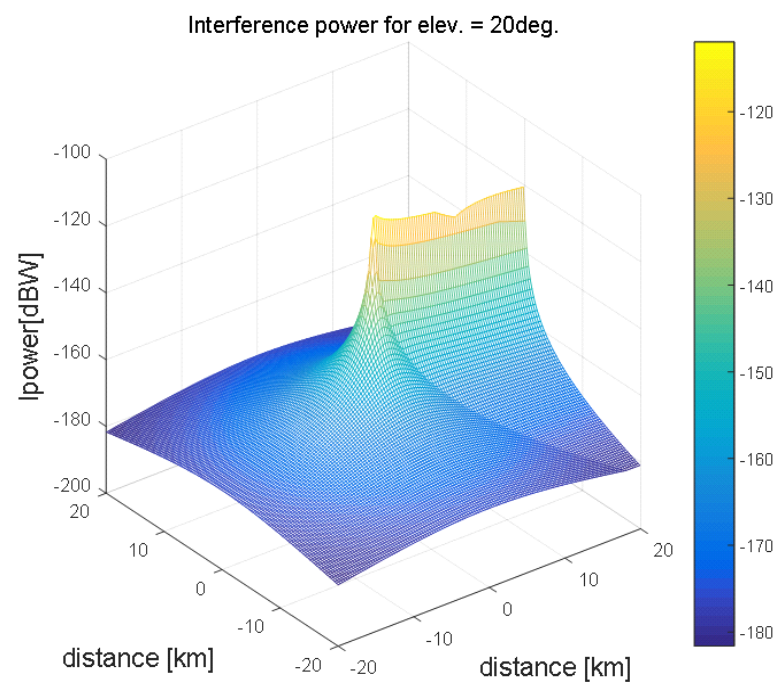

그림 6. 앙각이 $20^{\circ}$ 인 경우의 간섭전력 예

Fig. 6. An example of interference power with elevation angle of $20^{\circ}$.

표 5. 위성 지구국과의 공동사용 기준

Table 5. Sharing threshold for satellite earth station.

\begin{tabular}{|c|c|c|c|c|c|c|c|}
\hline \multicolumn{2}{|c|}{ Azimuth angle } & \multicolumn{2}{c|}{$0^{\circ}$} & \multicolumn{2}{c|}{$10^{\circ}$} & \multicolumn{2}{c|}{$20^{\circ}$} \\
\hline \multicolumn{2}{|c|}{ Elevation angle } & $10^{\circ}$ & $50^{\circ}$ & $10^{\circ}$ & $50^{\circ}$ & $10^{\circ}$ & $50^{\circ}$ \\
\hline \multirow{2}{*}{$\begin{array}{c}\text { Separation } \\
\text { distance }\end{array}$} & Type 1 & $43 \mathrm{~km}$ & $16 \mathrm{~km}$ & $3 \mathrm{~km}$ & $<1 \mathrm{~km}$ & $2 \mathrm{~km}$ & $<1 \mathrm{~km}$ \\
\cline { 2 - 8 } & Type 3 & $42 \mathrm{~km}$ & $15 \mathrm{~km}$ & $3 \mathrm{~km}$ & $<1 \mathrm{~km}$ & $2 \mathrm{~km}$ & $<1 \mathrm{~km}$ \\
\hline
\end{tabular}

분리거리가 멀수록, 지구국의 앙각이 높을수록, 두 시스 템간의 방위각이 클수록 간섭영향은 줄어들고 있다. 표 5 에 계산된 한 예를 보이며, 두 시스템이 주파수 공동사용 을 위해서는 앙각이 극히 낮은 $10^{\circ}$ 에서 FS 송신안테나 메 인빔이 위성지구국 수신안테나의 보어사이트 방향일 때 분리거리가 $43 \mathrm{~km}$ 를 필요로 하고 있다. 그러나 위성지국 국 안테나의 보어사이트 방위각을 $10^{\circ}$ 로 $\mathrm{M} / \mathrm{W}$ 송신국을 설치하면 위성지구국과의 분리거리를 $3 \mathrm{~km}$ 로 크게 줄여 나갈 수 있다.

\section{5-2-2 이동형 선박국에 미치는 간섭}

ITU-R Rec. SF.1650-1 ${ }^{[6]}$ 권고문서는 ESV(earth stations on board vessels) 시스템이 FSR(Fixed Service Receiver)에 간섭을 주지 않기 위한 해안 분리거리를 계산하기 위한

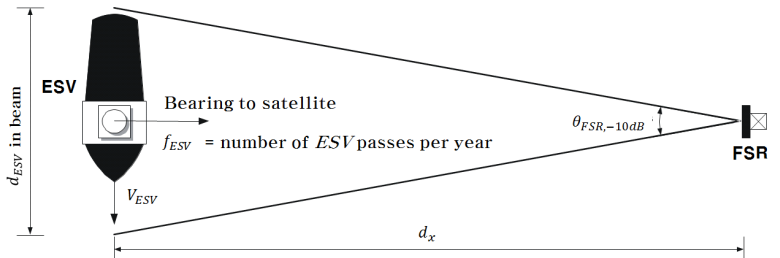

그림 7. 위성 선박국에 미치는 간섭

Fig. 7. Interference to a satellite vessel.

알고리즘을 제공하고 있으며, 이를 이용하여 그림 7과 같은 간섭 시나리오로부터 FS 시스템이 기존 위성 선박국에 대한 간섭영향을 평가할 수 있다. FS 시스템의 $-10 \mathrm{~dB}$ 빔폭 내에 위성 선박국이 운영되는 시간 및 $\mathrm{FS}$ 보어사이 트와의 진행 각도, 위성을 바라보는 앙각 등이 중요한 간 섭 파라미터라 할 수 있다. 위성 선박국에 수신되는 평균 전력 $\left(\overline{p_{r, 0}\left(\theta_{E}\right)}\right)$ 은 식 (2)와 같다.

$$
\begin{aligned}
\overline{p_{r, 0}\left(\theta_{E}\right)} & =\frac{e\left(\theta_{E}\right) g_{r \max }}{l_{452}(20) l_{F}} \frac{2 \pi \varphi_{m} r_{0}}{180 v_{E} \sin \theta_{0}} \frac{f_{E}}{8760}(0.5981) \\
& =R_{x} \frac{f_{E}}{v_{E} \sin \theta_{0}} e\left(\theta_{E}\right)
\end{aligned}
$$

여기서, $R_{x}=2.3833 \times 10^{-6} \frac{g_{r \max } \varphi_{m} r_{0}}{l_{452}(20) l_{F}}$

$e\left(\theta_{E}\right)$ : ESIM의 e.i.r.p $(\mathrm{dBW} / 40 \mathrm{kHz})$

$g_{r \max }$ : 수신 안테나 최대이득 $(\mathrm{dBi})$

$l_{F}: \mathrm{FS}$ 피더손실 $(\mathrm{dB})$

$l_{452}(20)$ : Rec. ITU-R P.452 전파손실 모델 $(p=20 \%)$

$\varphi_{r}$ : 오프축(off-axis) 각도 (도)

$\varphi_{m}:-10 \mathrm{~dB}$ 오프축 각도 (도)

랜덤하게 변하는 $\mathrm{ESV}$ 의 위성을 바라보는 안테나의 포 인팅 에러와 FSR을 향하는 방위각에 대한 통계해석을 통 해 FSR 수신 간섭기준 초과확률(outage probability)에 근 거한 간섭기준을 고려하는 것이 더욱 편리하다. $\mathrm{ESV}$ 의 앙각 및 방위각의 변동에 의한 FSR 수신 간섭기준 초과 확률 $I_{t h r}$ 은 다음과 같다.

$$
P_{\text {out }}=\operatorname{Pr}\left(I_{t}>I_{t h r}^{l}\right)=\int_{I_{t h r}^{l}}^{\infty} f_{F S}\left(I_{t}\right) d I_{t}
$$


여기서,

$$
\beta=R_{x 1} / I_{t h r}^{l}
$$

식 (3)은 단지 $0.01 R_{x 1} \leq I_{t h r}^{l} \leq 158.5 \varepsilon_{E}^{-2.5} R_{x 1}$ 범위 에서만 유효하며, 이보다 작거나 크면 초과확률 $P_{o u t}=1$ 또는 0 이다.

이동형 선박국의 방위각 변동에 따라 FS로부터 받는 간섭영향을 분석하기 위해 방위각의 랜덤분포 특성을 일 양분포로 가정하여 식 (4)의 $\beta$ 에 따른 이론적 초과(outage) 확률과 시뮬레이션에 의한 결과를 그림 8 에 보인다. 초과 확률이 작을수록 $\left(P_{\text {out }}=10^{-3}\right.$ 이하) 이론해석과 시뮬레 이션 결과가 일치하고 있지만, 그 확률이 클수록 오차가 점점 증가함을 알 수 있다. 여기서, 파라미터 $\beta$ 는 간섭기 준치, $I_{t h r}^{l}$ 에 대한 FS 시스템의 간섭 수신전력의 비를 나 타내고 있다. 이에 선박국의 앙각이 $20^{\circ}$ 에서 $30^{\circ}$ 로 증가 하면 초과확률 $0.1 \%$, 즉 $P_{\text {out }}=10^{-3}$ 기준으로 간섭 기 준치의 10 배에서 30 배 정도의 간섭 마진을 갖게 된다. 이 론해석 결과를 토대로 선박국의 앙각이 $25^{\circ}$ 인 경우, 초과 확률 $P_{\text {out }}=10^{-3}$ 에서 $10^{-2}$ 로 그 운영기준을 낮추면

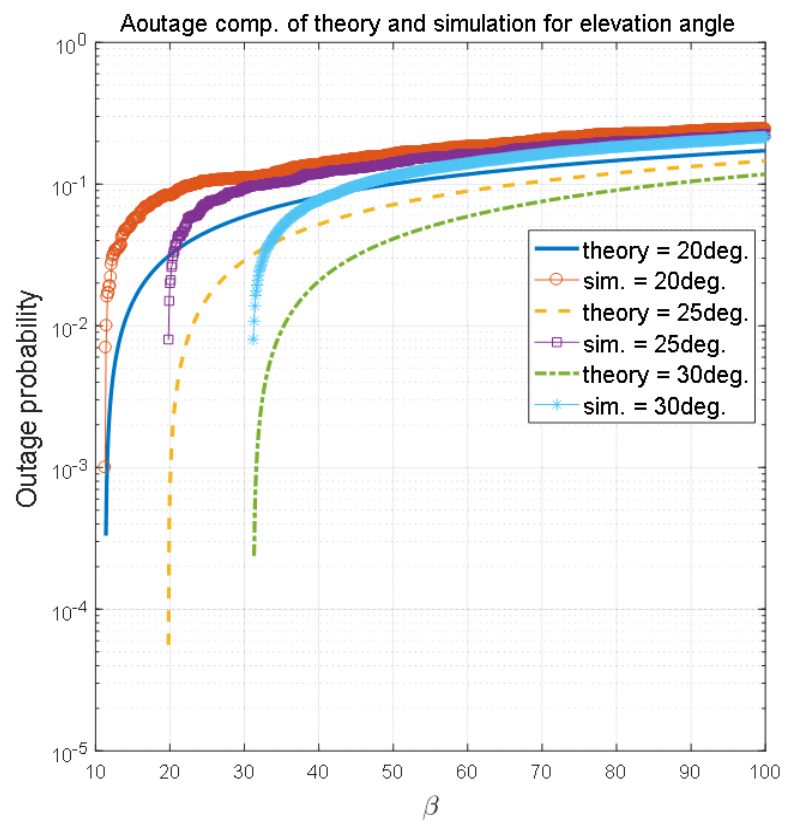

그림 8. $\beta$ 에 따른 초과확률

Fig. 8. Outage probability with $\beta$.
표 6. 위성 선박국과의 공동사용 기준

Table 6. Sharing threshold for satellite vessel.

\begin{tabular}{|c|c|c|c|c|c|c|c|c|}
\hline & \multicolumn{2}{|l|}{ Elev. angle } & \multicolumn{2}{c|}{ Path angle } & \multicolumn{2}{c|}{ Operation hour } & \multicolumn{2}{|c|}{ Speed } \\
\cline { 2 - 9 } & $20^{\circ}$ & $30^{\circ}$ & $1^{\circ}$ & $10^{\circ}$ & $\begin{array}{c}100 \\
\mathrm{~h}\end{array}$ & $\begin{array}{c}1,000 \\
\mathrm{~h}\end{array}$ & $\begin{array}{c}10 \\
\mathrm{~km} / \mathrm{h}\end{array}$ & $\begin{array}{c}50 \\
\mathrm{~km} / \mathrm{h}\end{array}$ \\
\hline $\begin{array}{c}\text { Separation } \\
\text { distance }\end{array}$ & $\begin{array}{c}32 \\
\mathrm{~km}\end{array}$ & $\begin{array}{c}22 \\
\mathrm{~km}\end{array}$ & $\begin{array}{c}31 \\
\mathrm{~km}\end{array}$ & $\begin{array}{c}12 \\
\mathrm{~km}\end{array}$ & $\begin{array}{c}4 \\
\mathrm{~km}\end{array}$ & $\begin{array}{c}12 \\
\mathrm{~km}\end{array}$ & $\begin{array}{c}17 \\
\mathrm{~km}\end{array}$ & $\begin{array}{c}8 \\
\mathrm{~km}\end{array}$ \\
\hline
\end{tabular}

수신 간섭전력 마진은 20 배에서 23 배 정도로 높아진다.

간섭평가에 의하면 선박국의 앙각이 낮을수록, $\mathrm{FS}$ 송 신국 안테나 보어사이트 방향으로 접근할수록, 선박국의 운영시간이 길수록, 선박국의 이동속도가 낮을수록 $\mathrm{FS}$ 송신에 의한 간섭영향이 크게 나타나고 있다. 표 6 은 가 용률 $99 \%$ (초과확률 $P_{o u t}=10^{-2}$ 기준)에서 두 시스템 간의 분리거리를 계산한 값이다. 이로부터 알 수 있듯이 두 시스템이 주파수 공동사용을 위해서는 여러 파라미터 조합으로부터 다양한 거리분석이 이루어져야 하며, 본 예 에서는 4 32 km 분리거리에 의한 주파수 공동사용이 가 능하다.

\section{5G 백홀용 재개발}

\section{6-1 새로운 링크 개발}

새로운 링크 설계에서는 용량을 증대시키기 위해 다음 의 3 가지 방안을 검토할 수 있다. 첫 번째는, 국내에서 이 용효율이 낮은 전형적인 $\mathrm{M} / \mathrm{W}$ 주파수 대역(17.7 19.7 $\mathrm{GHz}, 21.2 \sim 23.6 \mathrm{GHz}, 36.5 \sim 42.5 \mathrm{GHz}$ 대역)과 밀리미터 파 주파수 대역(71 $76 \mathrm{GHz}, 81 \sim 86 \mathrm{GHz}$ 대역)을 사용하 는 단거리 도시형 링크, 전형적인 중장거리 $\mathrm{M} / \mathrm{W}$ 주파수 대역을 사용하는 어그리게이션(aggregation) 링크의 개발 이다. 두 번째는, 광대역 채널화로 $14 \mathrm{GHz}$ 이상에서 56 $\mathrm{MHz}$ 및 $112 \mathrm{MHz}$ 채널 대역폭 제품 이용이다. 세 번째는, $\mathrm{H}-\mathrm{QAM}(1024 \mathrm{QAM}$ 이상)과 결합한 적응형 변조기술 사용, 스루풋(throughput) 용량 증대를 위한 헤더압축(header compression), 2 배의 주파수 용량을 실현하는 멀티채널 및 XPIC 적용 등이다.

그림 9는 $56 \mathrm{MHz}$ 채널 대역폭과 $256 \mathrm{QAM}$ 변조를 사용 하는 기본 형태에서 전송용량 증대를 가져오는 방안들의 


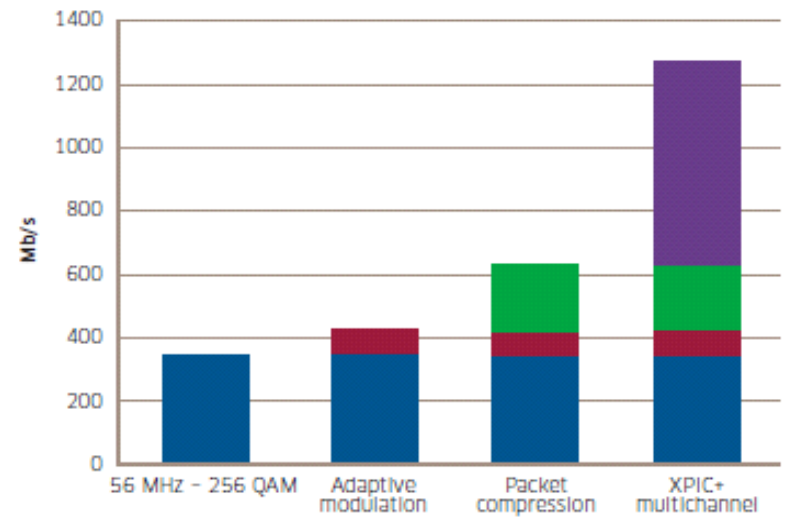

그림 9. 새로운 링크에 의한 전송용량 증대 ${ }^{[7]}$

Fig. 9. Promotion in transmission capacity with new links ${ }^{[7]}$.

효과를 나타내고 있다. 그림에서 1024QAM 적응형 변조, 헤더압축에 멀티채널 2+0 XPIC 기술을 사용하면 2017년 도 LTE-Advanced 매크로셀에서 요구되는 트래픽 수요기 준을 넘어서는 $1.3 \mathrm{~Gb} / \mathrm{s}$ 의 전송용량을 기대할 수 있다.

서비스 제공자들은 다음의 두 가지 방법 중 하나를 사 용하여 그림 1 의 최종 용량보다 2 배 또는 4 배의 전송용량 을 실현할 수 있다. $4+0$ 멀티채널 구성의 $4 \times 56 \mathrm{MHz}$ 채널 구현을 통하여 $2.5 \mathrm{~Gb} / \mathrm{s}$ 전송용량 증대와 $2+0$ 멀티채널 구성의 $2 \times 112 \mathrm{MHz}$ 채널구현을 통하여 $5 \mathrm{~Gb} / \mathrm{s}$ 전송용량 증대이다 ${ }^{[7]}$.

\section{6-2 멀티밴드 부스터}

$\mathrm{M} / \mathrm{W}$ 백홀 주파수로 사용될 수 있는 주파수 대역들은 전파특성에 의해 결정된다. 즉, 주파수가 높아짐에 따라 강우감쇄 및 자유공간손실이 증가하므로 높은 주파수에 서의 전송 거리는 제한적일 수밖에 없다. 우리나라도 아 열대성 기후로 접어들면서 시간당 $80 \mathrm{~mm} / \mathrm{h}$ 이상의 집중 호우를 고려하면 가용성 목표치를 $1 / 2$ 최대 링크용량으로 낮추어야 하는데, 6 42 GHz 대역에서 4096QAM 대신에 64QAM, $60 \mathrm{GHz}$ 및 70/80 GHz 대역에서 256QAM 대신에 $16 \mathrm{QAM}$ 의 적응형 변조기법을 고려해 나가야 한다.

주어진 홉 길이에서 전송용량을 증대시킬 수 있는 전 형적인 멀티밴드 조합은 다음과 같다. 약 $5 \mathrm{~km}$ 이하의 홉 길이에서 $18 \sim 42 \mathrm{GHz}$ 대역은 초광대역인 $70 / 80 \mathrm{GHz}$ 대 역과의 어그레게이션, $5 \mathrm{~km}$ 이상의 홉 길이에서는 협대

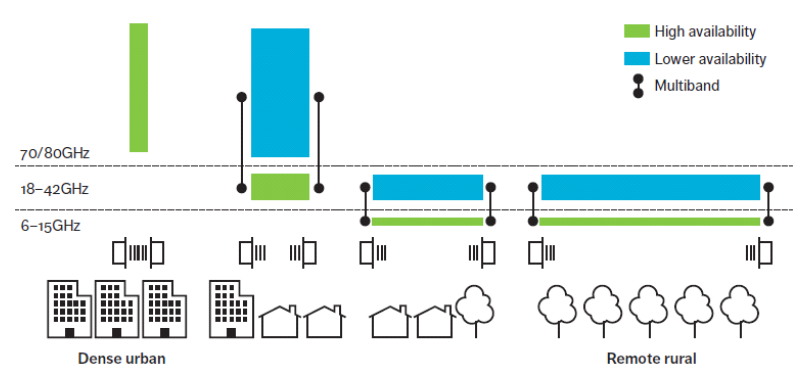

그림 10. 멀티밴드 $\mathrm{M} / \mathrm{W}$ 백홀 구성 예[7]

Fig. 10. Example of multi-band $\mathrm{M} / \mathrm{W}$ backhaul configuration $^{[7]}$.

역의 6 15 Ghz 대역과 광대역의 $18 \sim 42 \mathrm{Ghz}$ 대역과 어 그레게이션이 가능하다.

오늘날 높은 주파수 대역은 홉 길이 때문에 도시형 링 크로 제한적이어서 $8 / 11 \mathrm{GHz}$ 대역을 선호하고 있다. 이에 멀티밴드 부스터는 그림 10 에 보이는 바와 같이 비교적 장거리의 넓은 지역에서 높은 백홀 주파수 대역을 사용할 수 있도록 한다. 멀티밴드 부스터를 통해 정부에서도 주 파수 대역, 지형적 특성, 로컬 $\mathrm{M} / \mathrm{W}$ 홉 밀도에 웨이팅 펙 터(weighting factor)를 두어 면허 제도를 개선한다면 이용 이 저조한 고주파수 대역을 효율적으로 사용하게 될 것 이다 ${ }^{[7]}$.

\section{6-3 $100 \mathrm{GHz}$ 이상 주파수 개발}

2021 년까지 전세계 셀 사이트의 $65 \%$ 가 M/W 백홀 기술 을 사용하여 연결될 것이며, 전송용량 수요의 급속한 증 가에 따라 기술혁신에 의한 상당한 성능개선 및 기존 스 펙트럼의 효율적 이용이 요구되고 있다. 그 목표로서 100 $\mathrm{GHz}$ 이상의 스펙트럼을 개발하여 수 $\mathrm{km}$ 의 홉 길이로 여 러 응용과 이용 케이스(case)를 지원하기 위한 $100 \mathrm{Gbps}$ 전송용량을 추구하고 있다. 높은 주파수 대역은 전송거리 및 서비스 커버리지(coverage)에 있어서 제한적이지만, 일 반적으로 광대역의 주파수 대역폭을 제공하여 초고속 데 이터 전송용량을 갖게 된다. 현재 $70 / 80 \mathrm{GHz}$ 대역(71 76 $\mathrm{GHz} / 81 \sim 86 \mathrm{GHz}$ )은 그 인기가 폭발하고 있으며, 수 $\mathrm{km}$ 의 전송거리에 1 20 Gbps 전송용량이 가능하다. 한편, 100 $\mathrm{GHz}$ 이상의 스펙트럼은 $275 \mathrm{GHz}$ 까지 고정서비스에 할당 되어 있지만, 아직 채널지정은 이루어지지 않았다. 


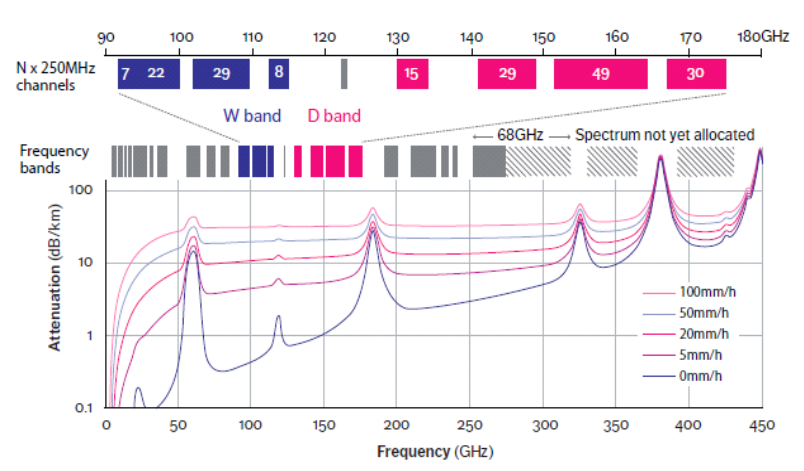

그림 11. 대기감쇄 특성[8]

Fig. 11. Atmospheric attenuation characteristics ${ }^{[8]}$.

그러나 유럽에서는 채널지정에 대한 제도 연구가 이뤄 지고 있으며, 92 114.25 GHz 및 $130 \sim 174.8 \mathrm{GHz}$ 대역을 검토하여 각각 $\mathrm{W}$ 및 $\mathrm{D}$ 대역으로 부르고 있다. $100 \mathrm{GHz}$ 이상의 스펙트럼은 그림 11에 보인 주파수 대역에서 사 이사이마다 빈 대역에 패시브(passive) 서비스, 즉 $\mathrm{EESS}$ (Earth Exploration Satellite Service) 및 RAS(Radio Astronomy Service)에 분배되어 있다.

가스흡수 손실특성은 $70 \mathrm{GHz}$ 이상에서 약간 증가하여 $\mathrm{D}$ 대역까지 $2 \mathrm{~dB} / \mathrm{km}, 275 \mathrm{GHz}$ 대역까지는 약 $4 \mathrm{~dB} / \mathrm{km}$ 단 위로 증가하고 있다. 자유공간손실도 함께 증가하여 70 $\mathrm{GHz}$ 이상에서 $\mathrm{D}$ 대역까지 $6 \mathrm{~dB}, 275 \mathrm{GHz}$ 까지 $11 \mathrm{~dB}$ 증 가하고 있어, $100 \mathrm{GHz}$ 이상의 주파수는 전파손실 면에서 좋지 않다.

한편, $275 \mathrm{GHz}$ 이상의 대역은 패시브 서비스로 분배되어 액티브(active) 서비스 이용은 배제되어 있다. 우선적으로 WRC-19에서 275 450 GHz 대역에 대해 육상이동 및 고 정서비스 응용으로 논의가 진행될 예정이다. 만일 275 $320 \mathrm{GHz}$ 대역이 고정서비스에 추가된다면, 그림 11에 보 이는 바와 같이 적절한 가스흡수 특성으로 연속의 68 $\mathrm{GHz}$ 대역폭을 확보 가능하다. 국내에서도 향후 $5 \mathrm{G}$ 시대 의 백홀 전송에 $100 \mathrm{Gbps}$ 를 지원할 수 있도록 $100 \mathrm{GHz}$ 이상의 대역에 적합한 미래의 혁신기술을 가능하게 하는 스펙트럼 제도 및 규정이 필요한 실정이다 ${ }^{[8]}$.

\section{VII. 결 론}

올해 전반기 $\mathrm{M} / \mathrm{W}$ 수요에 대해서는 채널변경 및 편파
조정 등을 통해 신규 채널지정이 가능했지만, $8 / 11 \mathrm{GHz}$ 대역에서의 주파수 사용채널은 포화상태에 이르렀다. 특 히, 백령도와 같은 특정 도서지역에서의 $8 \mathrm{GHz}$ 대역 채 널은 더 이상 지정이 어려울 것으로 예상되고 있다. 따라 서 중-장거리 전송거리를 요하는 도서지역의 지속적인 전송용량 증대 수요에 대처하기 위한 다음의 방안들이 향후 지속적으로 추진되어야 한다.

\section{7-1 공공용 $\mathrm{M} / \mathrm{W}$ 주파수 공동사용}

$\mathrm{M} / \mathrm{W}$ 중계대역 $(8 \mathrm{GHz})$ 과 인접해 장비교체 없이 활용 가능한 후보대역 중 무선국 이용현황, 운용지역, 기술(대 역폭, 출력 등) 및 운용특성(고정, 이동) 등을 고려하여 우 선적으로 7,110 7,725 MHz 대역을 검토하게 되었다. 이 대역은 지역적으로 공공용 $\mathrm{M} / \mathrm{W}$ 중계용으로 사용 중이지 만, M/W 중계는 서울, 부산 등 내륙에서 지역적으로 사용 하고 있어 평상시에 서해 및 남해 도서지역에서 공동사 용이 가능하다는 결론을 얻었다.

\section{7-2 5G 백홀 주파수 재개발}

$5 \mathrm{G}$ 백홀 링크 설계에서는 용량을 증대시키기 위한 모 든 가능한 메카니즘을 사용해 나가야 하며, 낮은 주파수 의 협대역 채널과 높은 주파수의 광대역 채널을 결합하 는 멀티밴드 부스터(multiband booster) 기술을 적용하는 게 바람직하다. 이와 같은 새로운 기술들은 $18 \sim 42 \mathrm{GHz}$ 대역이용의 증가뿐만 아니라, $70 / 80 \mathrm{GHz}$ 대역에서의 이 용을 크게 증가시켜 나갈 것이다. WRC-19 의제로 육상이 동 및 고정서비스 응용으로 $275 \sim 450 \mathrm{GHz}$ 대역이 검토되 고 있으며, 이미 252 275 GHz 주파수 대역은 고정서비 스에 분배되었다. 이에 국내에서도 $100 \mathrm{GHz}$ 이상의 주파 수 개발을 위해 미래의 혁신기술을 가능하게 하는 스펙 트럼 제도 및 규정을 마련하는 것이 매우 중요하다.

결론적으로 국내의 경우 서해안 지역은 도서거리가 멀 어 통신사업자들이 홉 길이가 긴 낮은 주파수 $\mathrm{M} / \mathrm{W}$ 대역 의 새로운 주파수 수요제기뿐만 아니라, 기존의 $6 \mathrm{GHz}$ 대역의 $\mathrm{M} / \mathrm{W}$ 장비 수명 만료에 따른 장비 대체 수요가 증 가하고 있다. 따라서 앞으로의 연구수행 방향은 이 수요 제기에 따른 해결방안 모색과 $7.2 \sim 7.725 \mathrm{GHz}$ 대역에서 의 공공 주파수 이용을 면밀히 검토한 후 $\mathrm{M} / \mathrm{W}$ 서비스와 
의 간섭분석 및 특정지역에서의 주파수 공동사용 방안을 마련해 나가고자 한다.

\section{References}

[1] C. J. Kim, Y. H. Kang, K. M. Kye, Y. S. Kim, D. K. Park, and S. Park, et al., "Analysis of spectrum sharing policy and spectrum usage rights," The Journal of Korean Institute of Electromagnetic Engineering and Science, vol. 24, no. 8, pp. 805-819, Aug. 2013.

[2] Y. H. Kang, D. Y. Lee, H. S. Seo, and J. Y. Park, "A study on the spectrum sharing and technical criterion of the microwave relay spectrum," Research on Broadcasting Communication Policy, Ministry of Science, ICT and Future Planning, 2014.

[3] Korea Communications Agency Report, "Analysis and implementation of frequency redevelopment for $\mathrm{M} / \mathrm{W}$ relay" 2017.

\section{강 영 흥 [군산대학교/정보전산원 원장]}

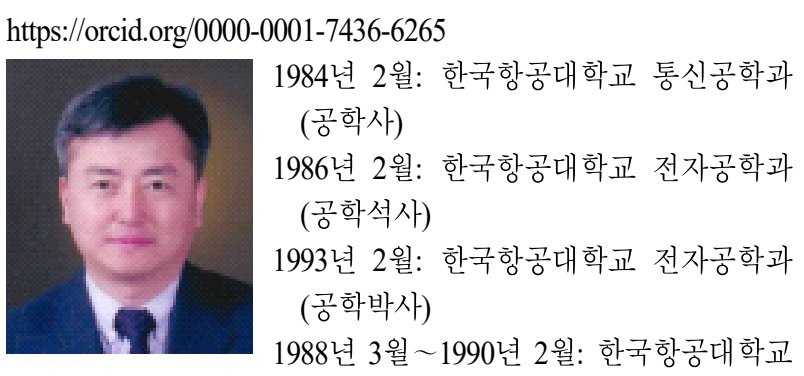

통신공학과 조교

1995년 8월 1996년 8월: 일본 오사카대학 객원교수

2003년 8월 2005년 2월: 영국 York대학 방문교수

1990년 4월 현재: 군산대학교 전자정보공학부 교수

2018년 3월 현재: 군산대학교 정보전산원 원장

[주 관심분야] 위성통신, 이동통신, 표준화
[4] Alcatel-Lucent, "Modern microwave: Enhancing capacity to keep up with demand.," 2014. http://www.tmcnet.com/ redir/?u=1011899.

[5] Ministry of Science and ICT, "M/W frequency utilization efficiency plan," Sep. 2017.

[6] The Minimum Distance from the Baseline beyond Which In-motion Earth Stations Located on Board Vessels Would not Cause Unacceptable Interference to the Terrestrial Service in the Bands 5,925 -6,425 MHz and 14 14.5 $\mathrm{GHz}$, ITU-R Rec. SF.1650-1, 2005.

[7] Ericsson Review, "Microwave backhaul gets a boost with multiband," Jan. 2016. https://www.ericsson.com/en/erics son-technology-review/archive/2016/microwave-backhaulgets-a-boost-with-multiband.

[8] Ericsson Review, "Microwave backhaul beyond 100 GHz," Feb. 2017. https://www.ericsson.com/en/ericsson-technolo gy-review/archive/2017/microwave-backhaul-evolution-rea ching-beyond-100ghz. 